\title{
ONLINE ONE-STOP GOVERNMENT
}

\section{$A$ working framework and requirements}

\author{
Maria A. Wimmer" and Efthimios Tambouris* \\ "University of Linz, Austria, * Archetypon SA, Greece
}

\begin{abstract}
Online one-stop government refers to the integration of public services from a customer of public services' point of view. It allows citizens, businesses and other authorities to have 24 hours access to public services from their home, their offices or even on the move using different access media and devices. The concept requires that all public authorities are interconnected and that the citizen is able to access public services by a single point even if these services are actually provided by different departments or authorities. One-stop government requires the reengineering of the public sector's processes towards online public services. It calls for a holistic framework that supports integrated modelling of electronic public services and synchronisation with the technical developments.
\end{abstract}

Key words: one-stop government, integrated online public services, holistic framework

\section{INTRODUCTION}

Electronic Government (e-Government) refers to the application of information and communications technology (ICT) to innovate and modernise the field of public administration. Hand in hand with the technological change, an organisational change and reengineering of traditional processes have to take place, though. So in a wider context, eGovernment is to be seen as a strategic development towards New Public Management and Business Process Reengineering, too.

Many countries worldwide have set the realisation of e-Government as one of their primary targets. The European Union, through the $e$ Europe initiative, recognises that e-Government - and also one-stop government could provide significant advantages to citizens, business and the public sector itself [4]. One-stop government is, however, a complex and 
multifaceted domain with amongst others technological, organisational, legal and social implications.

The project "An Integrated Platform for Realising Online One-Stop Government" (eGOV) is a research project aiming at the study of online one-stop government and at proposing technological and organisational solutions (www.egovproject.org, [17]). The main phases of this project are three: specifications, development and trials evaluation. The project has concluded the specifications phase and currently develops the one-stop portal, the service repositories, the Governmental Markup Language and the process models.

This paper reflects issues of online one-stop government and introduces a holistic development concept that has been elaborated for, and used within the eGOV project. Section 2 discusses general aspects of one-stop government and works into the main weaknesses of current approaches. Section 3 presents the holistic framework including the definition of the terminology used. In section 4, requirements of front- and back-office of an integrated platform for online one-stop government are listed. Finally, in section 5 we conclude with future work in the eGOV project.

\section{ONE-STOP GOVERNMENT}

One-stop government refers to the integration of public services from a citizen's - or customer of public services - point of view. This implies that public services are accessible through a single window even if they are provided by different public authorities or private service providers. By definition, the most important prerequisites of one-stop government are two. Firstly, public services must be integrated. Secondly, the customers must be able to access these services in a well-structured and well understandable manner meeting their perspectives and needs. One-stop government reflects a new structure of public administration as demonstrated in figure 1, which has significant impact on how public services are offered and delivered to the customer.

A significant characteristic of one-stop government is accessibility through multiple delivery means (or channels), including physical presence at designated offices, call centres, Internet, mobile devices, satellite TV etc. Online one-stop government allows citizens to have 24 hours access to electronic public services from their homes, libraries, schools, shopping malls or even on the move. The work reported in this paper concentrates on online one-stop government. 


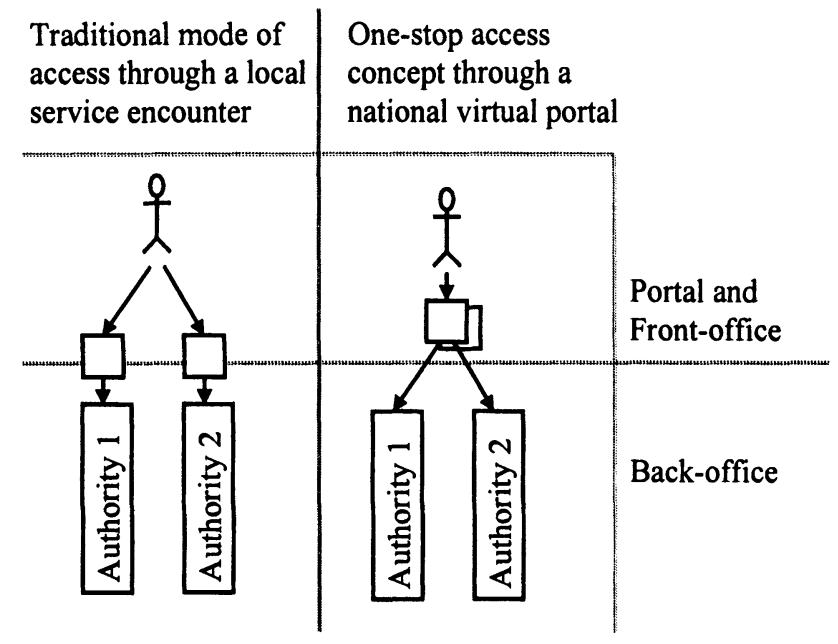

Figure 1. Online one-stop government: accessing public services through a central virtual portal

In online one-stop government, access to public services is realised through a governmental portal. National portals have been developed, or are under development, in an increasing number of countries [5], [16]. For example, most Member States of the European Union maintain a national governmental portal, e.g. UK (www.ukonline.uk), Austria (www.help.gv.at), France (www.service-public.fr), Portugal (www.infocid.pt) and Greece (www.polites.gr).

However, despite of the work conducted so far, online one-stop government is still in an infant stage. The main characteristics of online onestop government are also some of its main barriers. From a technical perspective, providing integrated services can only be realised if all public authorities are interconnected and their systems are interoperable. A promising solution to the problem of interoperability seems to be the eXtensible Markup Language (XML). Yet, XML technologies are still at their first steps and a lot of work is required before the technological part of this problem is solved.

Providing services in a citizen-oriented view calls for a new, serviceoriented design approach. The life-events or life-episodes approach has emerged as a metaphor to present electronic public services according to the citizens' needs and understanding.

The importance of online one-stop government in public service delivery is recently pointed out in a study of the European Commission [3]. This study was conducted in order to evaluate the maturity of 20 electronic public services in the Member States. These services were identified as the most important by the $e$ Europe initiative [4]. The evaluation study concluded that 
"the online development of public services can be enhanced by coordinated e-Government solutions which allow local service providers to take advantage of centralised online initiatives offering a single point of contact in the form of e-portals or ASP-related solutions (Application Service Providers), with a citizen/customer-oriented approach rather than a procedural approach".

In order to develop an integrated platform for realising online one-stop government, many aspects have to be born in mind. A holistic reference framework supports in investigating the many influencing issues including their interdependencies.

\section{HOLISTIC FRAMEWORK FOR SERVICE MODELLING}

The first step towards a holistic reference framework is a common terminology of concepts and expressions. It is the basis for a coherent understanding of the whole range of one-stop government facets. In the following subsection, the terminology developed within the eGOV project is presented.

\subsection{Terminology of online public services}

Life-events and business situations are an upcoming metaphor for structuring and defining specific online public services from a customer's point of view. However, in current work, semantic differences in the use of the terms processes, public services and life-events can be encountered. Hence, a typology to clearly distinguish the different terms is a prerequisite for developing online services based on a holistic approach. The left side of figure 2 demonstrates the overall relationship of the various expressions. The entry point of a user of online public services may be:

Life-events describe situations of human beings where public services may be required. They may be structured according to specific aspects regarding different citizen groups (e.g. birth, school, marriage, residence, personal documents, etc.). 


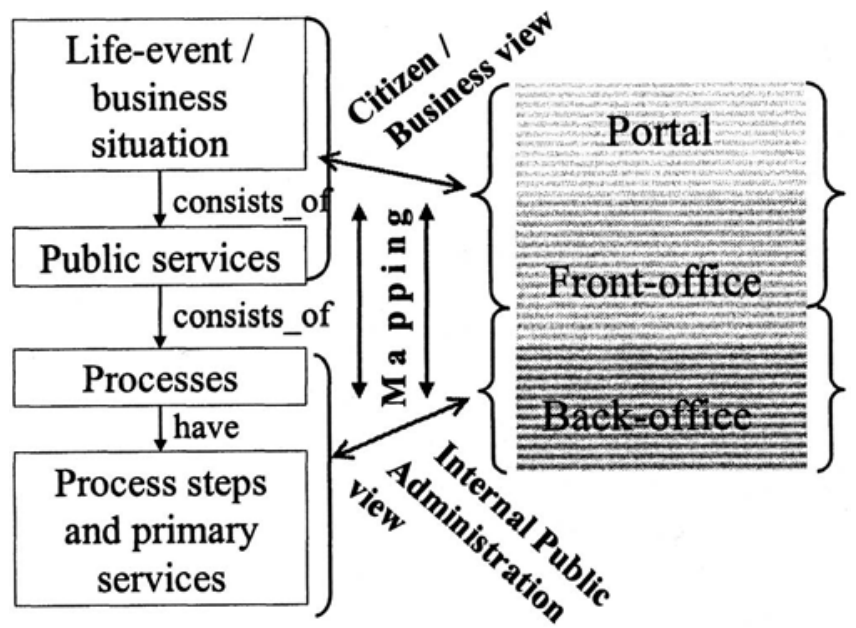

Figure 2. From life-events and business situations to processes: finding an appropriate mapping

Business situations describe topics of companies and self-employed citizens that may trigger public services or interactions with public authorities (taxes and customs, building permissions, employment of workers, etc.).

Life-events and business situations indicate the overall semantic content (i.e. information or public services) to facilitate the customer's navigation, orientation and search through the offers provided by public authorities on the one-stop government portal. However, the customer does not consume a life-event or business situation, since this general structuring concept only represents the overall entry point to specific public services at the portal.

Public services are the concrete products and services a customer is applying for or wants to consume. Public services are also the core concept to be handled by an integrated one-stop platform.

Public services reflect the external (customer oriented) point of view, whereas a process refers to the public administration's internal viewpoint, which also reflects the public administration's organisational and functional fragmentation, responsibility and domain expertise.

A process normally consists of several process steps that describe single tasks within a process. Process steps reflect the fine grained decomposition of a process. In regards to online public services, some process steps may be located at the front office. They may also be called primary services such as the identification of a user, the digital signature for an application of a public service, the payment for a public service, etc. 
Within an integrated platform for one-stop government, public services and information touch different internal units of an organisation on the one hand, and the customer's view on public services structured around lifeevents or business situations on the other hand. These internal vs. external views have to be mapped in a coherent way (cf. right side of figure 2) without

- disturbing organisational matters, responsibilities and expertise of public administrations or

- requiring the knowledge of public authorities' organisational fragmentation on the side of the external citizens or business clients.

A good understanding of administrative processes is crucial for adapting public services to one-stop government. Proper comprehension is no small problem, as in the field of operational administrative action, a huge variety of different processes can be encountered. Most processes are rather complex due to several causes (cf. [11]). To begin with, the extraordinarily complex goal structure of public administration has to be underlined. One dominant reason is the high degree of legal structuring of administrative work. It allows for a high degree of transparency and accountability, yet may hinder plain and common ways of re-engineering. Besides, in comparison to the private sector, the amount of work that only can be performed in cooperation with other agencies is rather high. Administration is working via a complex tissue of co-operation of acting entities. As a result, the mode of administrative processes and decision taking becomes very particular. Thus, administrative work appears as complex and rather strange. Here, an appropriate reference framework is required that facilitates the understanding of the complex structure and network of public services and governmental units.

\subsection{Holistic reference framework}

The holistic reference framework as shown in figure 3 is based on the socio-technical approach (cf. Cherns [1]), the BMRM of Schmid [15], the Information Architecture of Mok [12], and the discussion of Lenk [10]. What we can learn from these approaches is the multidimensional consideration (from the strategic layer to the technical layer) of distinct aspects (organisational, judicial, security, process modelling, access, services, workflow, etc.) and the core phases of an electronic process (from information to transaction and settlement - including an aftercare phase). The strengths of these approaches have been merged to the eGOV holistic reference framework. This concept supports the understanding of complex administrative processes from three distinct points of view:

Abstraction layers: different points of detail 
- Progress of process: different phases of an electronic process

- Different Views: distinct foci on issues

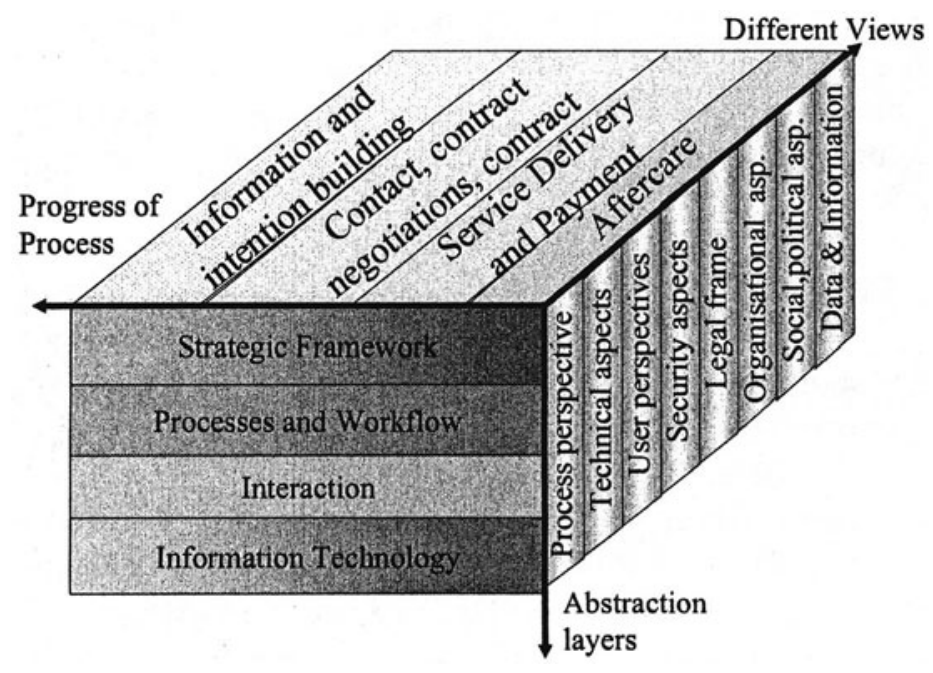

Figure 3: The eGOV holistic reference framework

\subsubsection{The abstraction layers}

A complex socio-technical system such as one-stop government can only be managed through different abstraction layers. The eGOV holistic approach integrates the following perspectives:

1. Strategic Framework: This layer represents the view on the basic organisational requirements (the strategy, basic roles, the strategic decisions and constraints) for realising a one-stop Government system. Concepts to support developments in this area are amongst others New Public Management [7], Human Relations Management and Business Process Reengineering [6].

2. Processes and Workflow: On this layer, the general business strategies and basic roles are substantiated. This means that processes and their workflow are specified. Thereby, the roles and their collaboration, the steps of the process, the co-ordination of input, throughput and output and the adaptation of the processes to the legal framework are defined and settled.

3. Interaction: On this layer, the interest lays on the concrete process performance, i.e. the integration of the process models, the people and information technology involved and the data and information objects belonging to the process. So, interaction and information flows are 
investigated. Further, the interfaces between different concepts (people, data \& information, processes, etc.) are object of study.

4. Information Technology: This layer is concerned with the technical implementation of the IT components of the one-stop government system such as the portal, the service repositories, a standardised data and information exchange format etc. It also contains the communication, transaction and transportation infrastructure including their interfaces respectively.

\subsubsection{The evolution of an administrative Process}

For quite some time, several (not necessarily contradicting) discussions on how to approach different stages in electronic service provision have been existing (e.g. the BMRM [15], the OL2000 [14], Lenk's discussion [10] and the EC benchmarking strategy [2]). The approaches can be generally divided into concepts that focus on aspects of development, i.e. simple information portals, providing communication facilities and, finally, fully realising transactions. The concepts refer to the maturity of electronic services (e.g. the EC list with the most important public services). The other group of approaches addresses different degrees or stages of electronic service consumption, i.e. from simple information provision via download of forms to interaction and finally transaction services. In these concepts, an electronic service is divided into different stages of progress (e.g. the BMRM). The OL2000 and Lenk also include an aftercare phase, i.e. full support for electronic service delivery does not end with the service delivery and payment, but incorporates also customer relationship management, complaints management, etc.

The eGOV reference framework enables an electronic public service to be approached in four phases:

1. In the information and intention building phase, the user searches for information regarding possible intended public services. S/he can read information about the service itself, how to apply for it, whom to contact to get more detailed information and what the preconditions are. Further, information is provided on the different possible ways to make a transaction (e.g. online; downloading a form and sending the form via ordinary mail; or appearing personally at the service counter) and about which documents $\mathrm{s} / \mathrm{he}$ has to provide. Despite of the one-way information consumption, the customer can get in contact with an authority in order to acquire further information regarding the procedure to apply for a specific pubic service, etc.

2. In the contracting phase, the user already knows what $s /$ he needs to do. $\mathrm{S} /$ he either fills in the online application form or downloads the 
corresponding form from the server and fills it in. Sometimes, contract negotiations may take place in order to set up the obligations of each partner (service level agreements). These agreements are signed in a contract and are obligatory for both sides. However, most times the citizen or business partner directly hands in the application for a public service, which is to be considered as the contract. This can be done by means of an online transaction, in written form electronically or via ordinary mail or personally at the administration counter. In case an electronic medium is used, attention has to be paid to authentification and authenticity. With this action, the customer activates an administrative process, where, at first hand, the public authority proves the completeness and correctness of the application. In case some material or data is missing or is incorrect, the applicant will be asked to refine the data or to provide the requested material. In case of acceptance, the application is passed from the front-office to the backoffice for further handling (see next phase).

3. In the service delivery and payment phase, the processes to complete the service are performed, the results are conveyed to the customer and the customer pays for the service. Possible results can be e.g. adjudicating a social benefit, issuing a document, transferring information, etc. This phase is the most complex and complicated phase within the four stages, since it has to realise different types of processes from simple and well structured routine processes to weakly structured processes of decision making and negotiation (cf. [11], [18]).

4. The last phase of the eGOV holistic reference framework addresses an aftercare phase, where aspects of citizen (or customer of public administration) relationship management and complaints management are addressed. Furthermore, aspects of filing and information delivery for statistical purposes within the net of public authorities have to be supported. Often, a public service is not a matter of a single consumption, but of repeated contact and of e.g. monthly delivery of service (e.g. social subsistence benefits, grants for studies, etc.). Aspects of this concern are to be taken care of in this phase, too.

The user does not need to run through all above-mentioned phases. On the one hand, depending on his/her situation the user might only want to gather information about a process (only information phase) or $\mathrm{s} / \mathrm{he}$ might already know the procedure to apply for a service and, hence, starts with filling in an online form (starting with the contracting phase). On the other hand, also the aftercare phase is not always required and may not be performed by an authority. The two basic criteria for navigating through these four stages of progress of an online public service are 1) the level of 
know-how the customer already has about a specific service and 2) the characteristics of the service under consideration.

\subsubsection{Different viewpoints}

In order to carefully deliberate the requirements and developments for an integrated platform for online one-stop government, a distinction of different views is required. Apart from the principal focus on the processes and services of public administration, the eGOV holistic reference framework supports the following foci:

1. technical viewpoint (focusing on the technical implementation of the system)

2. view on people (deliberating the needs and requirements for the different user groups: citizens, businesses, public administration employees)

3. security aspects (deliberating the security requests for public services and for the one-stop government system)

4. legal issues (investigating legal constraints, frames etc.)

5. organisational aspects (structural fragmentation of public administration and division of domain expertise, responsibilities, etc.)

6. social and political aspects (considering political decisions, social impacts, etc.)

7. view on data and information (designing information objects, databases etc.).

With this distinction of different perspectives, a careful deliberation of the various aspects shaping and impacting one-stop government systems should be guaranteed.

\section{REQUIREMENTS FOR ONLINE ONE-STOP GOVERNMENT}

Based on the eGOV holistic reference framework and the general discussion in section 2, the following key requirements have been derived for the online one-stop government platform to be implemented in eGOV:

- customers can access public services via a single entry point even if the services are provided by different departments or authorities

- customers access the services in terms of life-events without needing to know to which public authority the functional competency is assigned to

- different stages can be approached (and monitored) for a service: simple what-is, what-is-required and where-to-go information on the service; possibility to contact people and to get further information (information and intention building); downloading and handing in forms for 
applications of public services (contracting); handling a complete service (transaction); citizen relationship management or complaints management (aftercare)

- public authorities are interconnected

- access is possible via different media channels and devices

- official proceedings are adapted for Internet performance

- front- and back-office are smoothly integrated (avoiding media breaks)

- underlying laws and prescriptions are clarified and updated

- administrative terms are translated into the customer's jargon.

To succeed with one-stop government, the specific needs of the different (external) user groups (i.e. citizens, businesses and other public administrations) need to be investigated and addressed properly. The ISO standards 13407 [8] and 9241 [9] have been the basis for specifying the user requirements within $\mathrm{eGOV}$ :

1. Services relevant for the user group (e.g. functionality): It should be clear for the user what each service is good for and how it works (functionality). Ideally, the user recognises intuitively how to use the service (awareness), but additional help should be available if needed.

2. Technical aspects at the user's site (e.g. security): The user is expected to have and be able to use certain technology. In case of an online onestop platform, the user is expected to have a browser and certain technical equipment. It should be mentioned that the level of technology demanded from the citizen should be as low as possible while the level for businesses and public authorities can be higher.

3. Reliability: The user should be able to rely on the way the system works and to count on its timeliness. Therefore, the system should be predictable, i.e. the user should not be surprised by the way the system reacts. Further, the system should inform the user that something is going on and what is going on (feedback). Finally, it should deliver the expected results within a reasonable, short time.

4. Multilinguality: The system should not be restricted to one single language. The user should be able to choose the language in which $\mathrm{s} / \mathrm{he}$ wants to use the system. However, since multilinguality is a costly issue, a reasonable trade-off has to be defined for how many languages the system should offer in respect to the context it will be used.

5. Usability: The user should have the feeling that the system is easy to use, that $s /$ he can operate it intuitively, that interaction objects have a consistent behaviour (look and feel) and that the system does what $\mathrm{s} / \mathrm{he}$ wants in an adequate time with only little effort of the user. In specific, the standard ISO 13407 [8] defines usability as the "extent to which a product can be used by specified users to achieve specified goals with effectiveness, efficiency and satisfaction in a specific context of use". In 
this respect, effectiveness refers to the accuracy and completeness with which users achieve specific goals; efficiency put the resources expended in relation to the accuracy and completeness with which users achieve goals; and satisfaction describes the freedom from discomfort and positive attitudes to the use of the product.

Nielsen [13] defines further influencing criteria for usability:

Learnability: The system should be easy to learn so that the user can rapidly start getting some work done.

Memorability: The system should be easy to remember, so that the casual user is able to return to the system after some period of not having used it, without having to learn everything all over again.

Error rate: The system should have a low error rate, so that users make few errors during the use of the system, and so that if they do make errors they can easily recover from them. Further, catastrophic errors must not occur.

6. Navigation concepts reflecting the specific user needs (life-event metaphor, business situations, thematic structures, etc.): The navigation concept must be designed in a way that the user knows where $\mathrm{s} / \mathrm{he}$ is at the moment

what $\mathrm{s} / \mathrm{he}$ can do at this point where $\mathrm{s} /$ he can go next how s/he can get there how to get back

at any time when $\mathrm{s} / \mathrm{he}$ is working with the system.

Implementing above listed requirements within an integrated platform for online one-stop government is an illustrious goal. Currently, we are still far away from such next generation virtual administrations reachable with a few simple mouse-clicks. This may be due to many aspects that still need clarification [18]: setting up the appropriate legal grounding, adjusting the access rights and access mode to highly sensitive data (which is not just a matter of security, but also of public-private and public-public partnerships, of the current laws, of the heterogeneity of systems and data formats, etc.), justifying red tape problems, and so on.

Providing a common semantic typology and document interchange format over the global Web is another prerequisite for the one-stop concept. Within the eGOV project, a standardised exchange format for administration specific content (termed GovML) is developed within a specific work package. For more details on GovML, the interested reader is referred to the technical reports available at www.egovproject.org. 


\section{FUTURE WORK}

The strong impact of IT and the resulting improvements and visions of eGovernment will start a process of completely rebuilding the state power all over the world. However, these changes will only lead to satisfaction of all participants if the whole fan of influences is born in mind during the establishment of such a modern virtual administration. With the holistic approach introduced in this paper, the eGOV project partners balance the technological development (i.e. the implementation of the technical components) with non-technical assets (integrated service modelling, Governmental Markup Language, test and evaluation with the users in three European countries).

So far, the first phase of the project has been concluded with the requirements specification of 1) the technical components and 2) the online public services, upper level specification of GovML and user requirements. Currently, the second phase has commenced with the implementation of the portal, the service repositories, service runtime environment and the integrated service models.

\section{ACKNOWLEDGMENTS}

eGOV (An Integrated Platform for Realising Online One-Stop Government, Grant IST-2000-28471) is a two-years EC co-funded RTD project with the following partners: Siemens Austria (A); Archetypon S.A. (EL); TietoEnator Corporation (FIN); IKV ++ GmbH (D); University of Linz (A); National Centre for Scientific Research "Demokritos" (EL); Hellenic Ministry of Interior (EL); Municipal Technology Company of Amaroussion (EL); University of Lausanne (CH); Austrian Federal Computing Center (A).

\section{REFERENCES}

[1] Cherns, A. The principles of sociotechnical design. Human Relations 29(8): 1976, pp. 783-792.

[2] eEurope. Common list of basic public services, March 2001, available at http://europa.eu.int/information_society/eeurope/action_plan/pdf/basicpublicservices.pdf [10/01/2002].

[3] eEurope. Web-based Survey on Electronic Public Services, available at http://europa.eu.int/information_society/eeurope/egovconf/documents/pdf/eeurope.pdf [10/01/2002]. 
[4] eEurope2002. An Information Society For All, Action Plan of the European

Commission, available at http://europa.eu.int/information_society/international/candidate_ countries/doc/eEurope june2001.pdf [10/01/2002].

[5] Eymeri, J-M. The Use of Information and Communication Technology in the Public Administrations of the EU Member States, Report of the European Institute of Public Administration, Maastricht, 2000.

[6] Hammer, M., J. Champy. Reengineering the Corporation: A Manifesto for Business Revolution, Harper Business, New York, NY. 1993.

[7] Hunziker, A.W. Die Prozessorganisation in der öffentlichen Verwaltung, New Public Management und Business Reengineering in der schweizerischen Bundesverwaltung, Schriftenreihe des Instituts für betriebswirtschaftliche Forschung an der Universität Zürich, Haupt Verlag, 1999.

[8] ISO/DIS 13407. Human-centred design processes for interactive systems. International Standards Organisation, 1999.

[9] ISO 9241. Ergonomic Requirements for Office Work with Visual Display Terminals (VDTs), 1998.

[10] Lenk, K. Individualisierung, flexible Produktion und Standardisierung: VerwaltungsEngineering als Schlüsselfunktion im e-Government, Präsentation zu einem Workshop über "Vereinheitlichung kommunaler Geschäftsprozesse - Erarbeitung gemeinsmer Lösungen durch MEDIA@komm", Berlin, 3-4 May 2001.

[11] Lenk, K., Traunmüller, R., Wimmer, M. The Significance of Law and Knowledge for Electronic Government, in Grönlund (ed.), "Electronic Government - Design, Applications and Management", Idea Group Publishing, 2002, pp. 61-77.

[12] Mok, C. Designing Business: Multiple Media, Multiple Disciplines, MacMillan Computer Publications, 1996.

[13] Nielsen, J. Usability Engineering, Academic Press, San Diego, 1993.

[14] OL2000. The reference model for the electronic public counter of the Public counter 2000 programme. Report of the OL2000 programmabureau Overheidsloket 2000, Den Haag, http://www.OL2000.nl/ [14/8/2001].

[15] Schmid, B. Elektronische Märkte - Merkmale, Organisation, Potentiale. In Hermanns, A; Sauter, M. (Eds.), Management-Handbuch Electronic Commerce, München: Vahlen 1999. [16] Suter, W. Bericht über die Studie zu den Guichets Virtuels in der Welt, Studie der Schweizerischen Bundeskanzlei (Copiur), available at http://www.admin.ch/e-gov/de/GV/ documents.php [10/01/2002].

[17] Tambouris, E. An Integrated platform for Realising Online One-Stop Government: The eGov Project. In Proceedings of the DEXA International Workshop On the Way to electronic Government. IEEE Computer Socity Press, Los Alamitos, CA, 2001, p. 359-363.

[18] Wimmer, M., Traunmüller, R., Lenk, K. Electronic Business Invading the Public Sector: Considerations on Change and Design. In Proceedings of the 34th Hawaii International Conference on System Sciences (HICSS-34), Hawaii, 2001. 